\title{
Challenges in lung cancer screening: a review of implemented programs
}

\author{
Deven C. Patel ${ }^{1}$, Meghan Ramsey ${ }^{2}$, Anuradha Phadke ${ }^{3}$, Natalie S. Lui ${ }^{1}$ \\ ${ }^{1}$ Division of Thoracic Surgery, Department of Cardiothoracic Surgery, ${ }^{2}$ Division of Pulmonary and Critical Care Medicine, Department of Medicine, \\ ${ }^{3}$ Division of Primary Care and Population Health, Department of Medicine, Stanford University School of Medicine, Stanford, CA, USA \\ Contributions: (I) Conception and design: DC Patel, NS Lui; (II) Administrative support: DC Patel, NS Lui; (III) Provision of study materials or \\ patients: DC Patel, NS Lui; (IV) Collection and assembly of data: All authors; (V) Data analysis and interpretation: All authors; (VI) Manuscript \\ writing: All authors; (VII) Final approval of manuscript: All authors. \\ Correspondence to: Natalie S. Lui, MD. 300 Pasteur Drive, Falk Cardiovascular Research Institute, Stanford, CA 94305, USA. Email: natalielui@stanford.edu.
}

\begin{abstract}
Lung cancer screening (LCS) with annual low-dose computed tomography has been shown to have a mortality benefit in high-risk individuals. After publication of the National Lung Screening Trial in 2011, the United States Preventive Services Task Force recommended LCS in 2013, and Medicare began to cover it in 2015. The body of literature supporting LCS continues to grow; most recently the Dutch-Belgian LCS trial reaffirmed the substantial long-term reductions in mortality. Despite this, the rate of enrollment remains extremely low due to challenges at the patient, provider, and medical system levels. Several prominent organizations, including the American Association for Thoracic Surgery and the American Thoracic Society, have provided guidelines to develop a robust LCS program. The primary tenets include a structured referral network, multidisciplinary collaboration, comprehensive patient coordination and followup, standardized reporting and patient data management, and quality assurance. Numerous institutions in a variety of settings have used these guidelines and employed strategies of their own to improve the success of their respective LCS programs. This review outlines the challenges that currently exist, summarizes the principles of effective LCS, and details the experiences of several existing LCS programs in a variety of healthcare settings.
\end{abstract}

Keywords: Lung cancer screening (LCS); challenges; implemented programs

Received: 04 March 2020; Accepted: 02 June 2020; Published: 25 February 2021.

doi: $10.21037 /$ ccts-20-47

View this article at: http://dx.doi.org/10.21037/ccts-20-47

\section{Introduction}

Lung cancer is the most common cause of cancer-related death in the world, and smoking is the most prevalent risk factor (1). Although the prevalence of smoking has declined over the last few decades, a staggering $37 \%$ of adults in the United States are current or former smokers (2). Despite the knowledge of increased risk in this population, at the time of diagnosis, lung cancer is often already in an advanced stage with 5 -year survival as low as $15 \%(3-5)$. In the early 1970s, the National Cancer Institute sponsored several large scale studies to evaluate the utility of using chest X-ray film and sputum cytology for lung cancer screening (LCS), however, these studies failed to demonstrate any reduction in mortality $(6,7)$.

In 2011, the National Lung Screening Trial (NLST), a multicenter randomized controlled trial, established that screening with annual low dose chest computed tomography (LDCT) provided a $20 \%$ relative mortality reduction in individuals at high-risk for developing lung cancer (8). In addition, a $6.7 \%$ reduction in all-cause mortality was demonstrated by the NSLT, the highest seen across all cancer screening modalities $(8,9)$. The number needed to screen with LDCT to prevent one death from lung cancer is 320 (10). For comparison, the number needed to screen to prevent one death from breast or colon cancer is 1,904 
and 1,250 respectively $(11,12)$.

Given this evidence, in 2013, the US Preventative Services Task Force recommended screening for high-risk individuals, using the NLST criteria, with the addition of expanding the upper age limit to 80 years (13). Several professional societies such as the National Comprehensive Cancer Network (NCCN), and American Association for Thoracic Surgery (AATS), and American Thoracic Society (ATS) have all published similar guidelines $(14,15)$. In 2015, the Centers for Medicare and Medicaid Services (CMS) began covering LDCT LCS imaging, with the caveat that several requirements were met, such as smoking cessation counseling and participation in a national registry. Providing additional support to these guidelines, the recent publication of the NELSON trial (Dutch-Belgian LCS trial) reaffirmed the benefits of LCS, demonstrating a $24 \%$ and $33 \%$ mortality reduction in men and women respectively over a 10 -year follow-up period (16).

Despite the convincing benefits of LCS in high-risk patients, only $3.9 \%$ of eligible patients in the United States are successfully enrolled into a screening program (17). Several groups have used anecdotal, retrospective, and mixed methods data to identify the barriers to LCS (18). LCS programs have generally not yet had the same success as the cost-effective, population-based screening programs for breast, cervical, and colorectal cancer (19). This review outlines the challenges that currently exist, summarizes the principles of effective LCS, and details the experiences of several programs in a variety of healthcare settings.

\section{Challenges in LCS}

Regardless of the convincing evidence supporting annual LDCT scans for high-risk patients, there continues to be a discordance in enrollment (17). Due to the complex nature of LCS, the list of potential barriers are several-fold. Challenges can be categorized into issues at the patient, provider, and system level (20).

Patients themselves are often unaware of LCS, or choose not to be screened due to fear of a cancer diagnosis or concerns about cost. Using semi-structured interviews, Simmons et al. discovered a substantial number of highrisk individuals had never heard of LDCT LCS, nor had a healthcare provider mention the concept of screening to them (21). Participants also noted fear of a cancer diagnosis, as well as concerns of costs and insurance coverage for LCS. These findings were supported by a recent qualitative analysis examining a high-risk population of diverse and low income outpatients, who reported an insufficient understanding of the purpose of LCS, and desired personalized information that focused on the benefits and harms of enrolling (22).

Unique to LCS, eligibility is based on high-risk behavior, namely long-term heavy smoking, differing from colon and breast cancer screening which is primarily based on age. In this context, the perceived stigma associated with high-risk smoking behavior may lead to decreased patient engagement and participation in LCS $(23,24)$. Additionally, high-risk smoking behavior is more prevalent in lower socioeconomic tiers (25). These individuals have fewer financial and transportation resources, opportunities to take time off from work, and less social support to aid in facilitating preventative care and LCS (26).

Primary care physicians (PCP) serve as the first line of contact in addressing preventative care measures and identifying individuals who may qualify for LCS. However, known barriers at the provider level include limited knowledge regarding eligibility and the considerable time involved in discussing the LCS process with patients (21). In addition, there continue to be fractions of PCPs who still question the benefits of the NLST trial given the high false positive rate (27). PCPs also face a lack of national endorsement by national organizations such as the American Association of Family Practitioners (AAFP) (28). The AAFP has concluded that the current evidence on LCS is insufficient to recommend for or against LCS with LDCT in high-risk individuals based on age and smoking history (29). Attempts to improve physician awareness have included focused provider outreach and education by LCS program champions, however, the efficacy of this effort is unclear (30,31).

At the system level, a robust infrastructure is needed to seamlessly integrate several specialties and ancillary resources. This may entail comprehensive cancer centers, as discussed previously, or implementing sound referral policies and establishing a network of providers that remain in close communication to follow-up and manage positive findings. Additionally, LCS is resource intensive requiring considerable ancillary personnel and equipment. For instance, the number of CT scanners can impact a health system's scalability and ability to effectively screen patients (20). In this context, it is also important to note that insurance coverage of LCS requires American College of Radiology (ACR) CT accreditation. An LCS program must receive a passing score in several areas of evaluation including: personnel qualifications, quality control/ 
Table 1 Components of an effective lung cancer screening program

Structured referral network

Multidisciplinary collaboration

Comprehensive patient coordination and follow-up

Standardized reporting and patient data management

Quality assurance

quality assurance, and image quality (32). Additionally, accreditation requires the use of Lung-RADS or a similar structured reporting and management system. Accreditation should provide patients and referring providers assurance and standardization in the receipt of high quality screening and recommendations for appropriate follow-up care (33).

Furthermore, some health system challenges stem from disparities in health policy. For instance, LCS is not often prioritized by health systems as it is not recognized by national healthcare performance metrics. The CMS implemented Merit-Based Incentive Payment System (MIPS) program compensates health systems based on performance in variety of quality measures (34). As a component of the program's preventative care initiative, screening rates for colon, breast, and cervical cancer are factored into a health system's performance. However, LCS has not yet been recognized as a preventative care measure by the MIPS program. This impedes health systems from making LCS as high of a priority as other cancer screening programs.

\section{Defining the ideal LCS program}

Several groups have offered perspective and expert opinion of a high quality LCS program, often through a variety of descriptors ranging from pillars to key components of success (20,31,35-38). The Thoracic Oncology Assembly of the American College of Chest Physicians (AACP) and the American Thoracic Society (ATS) identified several core components of an effective LCS program using evidence-based reviews and expert opinion outlined in an issued policy statement (35). Common themes include structured referral network, multidisciplinary collaboration, comprehensive patient coordination and follow-up, standardized reporting and patient data management system, and implementation of quality assurance measures (Table 1).

A strong referral network is critical to the viability of an LCS program. The onus of identifying eligible patients primarily falls on the shoulders of PCP, as a component of preventative patient care. Thus, the ideal LCS program has a strong investment from the primary care community and offers policies and logistical support to facilitate the referral practices of PCPs (31). A number of educational resources have been developed and can be disseminated to providers to promote adherence to the national screening guidelines. Increased PCP education regarding the benefits of LCS, insurance coverage guidelines, and shared decision making process may lead to increased referrals into an LCS program (30).

A multidisciplinary presence is integral to the success of an LCS program (38). Typically, representation is needed from primary care, pulmonary medicine, medical oncology, thoracic surgery, radiology, pathology, smoking cessation counselors, and nurse coordinators. Often representatives from most of these groups will convene at routinely scheduled tumor board or lung nodule meetings. Given the importance of multidisciplinary collaboration in implementing an effective screening program, comprehensive LCS centers afford the opportunity to deliver shared decision making, imaging, interpretation, and management within a single venue for a patient (30). Thereby providing patients a "one-stop shop" to facilitate LCS in a convenient manner. A caveat to the aforementioned comprehensive cancer center is the significant resources and infrastructure needed to create and maintain such a program.

Due to the inherent invasive nature of thoracic surgery, the specialty is often the last to be consulted and involved in guiding care for a nodule discovered on a screening LDCT scan. However, it is imperative that thoracic surgeons are involved early, as their expertise and management of positive findings on an LDCT can optimize the delivery of care for a patient (5). Moreover, excessive and unnecessary use of diagnostic resources and interventional procedures can be avoided when a multidisciplinary team is in place to investigate and manage nodules discovered on a LDCT (39). For example, a patient with a lung nodule that is highly suspicious for lung cancer may prefer diagnostic wedge resection followed by lobectomy, rather than percutaneous biopsy with the possibility of a false negative result.

In terms of patient coordination and follow-up, a patient navigator (often a mid-level provider in the department of radiology, medicine, pulmonology, or surgery) is essential to the success of a program $(31,40)$. They are responsible for ensuring referring providers adhere to recommendations 
stated in the radiology report, assisting patient referral to the appropriate specialty and provider from the clinical management team, and coordinating annual follow-up for negative scans.

A standardized reporting system is a vital component to the efficacy of an LCS program. Radiology reports for LDCT should communicate pertinent positive and negative findings, as well as incorporate management algorithms (35). The most commonly used structured reporting system is the American College of Radiology Lung CT Screening Reporting and Data System (Lung-RADS). It is recommended that at least $90 \%$ of LDCT scans performed within an LCS program be reported using a structured system in order to minimize variation in the management of nodules and permit the opportunity for consistent and uniform care $(35,41)$.

Lastly, a robust quality improvement program is not only a requirement by the CMS, but an imperative asset to ensure reliability and effectiveness of a screening program. The ATS/AACP recommend review of an LCS program's screening data and adherence to the components discussed above on an annual basis by an oversight body to determine the level of compliance and areas of deficiency (35). Collected screening data should include outcomes of testing (complications and number of cancer diagnoses), tumor characteristics, and treatment patterns (35). Furthermore, as a quality metric, it is recommended at least $90 \%$ of screened individuals should meet USPSTF eligibility guidelines (35).

\section{Experiences in implementing LCS programs}

Several groups have established LCS programs in a variety of health care systems and socioeconomic settings in recent years. These published efforts offer invaluable information including points of success, challenges, and pitfalls that may be avoided in the future by others attempting to implement an LCS program of their own. Many of the programs reiterate the policies and suggestions put forth by the AACP/ATS previously discussed. A brief summary of selected studies is presented in Table 2 .

Gaps in patient and provider knowledge regarding LCS were challenges encountered by several programs in a variety of settings ranging from the Veterans Affairs (VA) health system to community and academic institutions $(32,42,44,48,49)$. Batlle and colleagues encouraged new LCS programs to invest in strategic marketing campaigns to promote awareness of its existence and the inherent benefits (32). Suggested cost-effective opportunities included grand rounds, patient educational seminars, social media outreach, and in-person visits with local physician practices. In addition, the latter facilitates the development of a robust physician referral network among PCP. In the aforementioned implemented program, one-third of the patients enrolled into LCS were directed through non-physician sources including newspapers, magazine advertisements, radio commercials, social media, and word of mouth (32). Simmerman et al. described the development of a Cancer Community Awareness \& Access Research Education program to promulgate the concept of LCS to minorities and underserved populations (45). In addition to patient directed campaigns, continued provider medical education is paramount as well. Previous qualitative studies have documented a clear gap in LCS guidelines and reimbursement knowledge (50). A recently established community LCS program discovered $22.4 \%$ (80/357) of the patients it had screened through referral were ineligible per NCCN and USPSTF guidelines (43). Similar findings were mirrored in LCS programs implemented in academic health systems as well $(44,49)$.

Coordinating care for patients with positive findings on LDCT was another commonly encountered challenge $(32,44,47)$. Solutions encouraged by several programs included hiring nurse navigators and advanced practice nurses (APN) to direct patients to the appropriate clinicians and imaging, as well as ensuring appropriate follow-up given screening should be done on an annual basis $(32,46,48)$. Nurse navigators have been described as the foundation of specialized LCS programs, as they are responsible for patient counseling, organizing clinical results, and mediating patientphysician interactions (51). One of the successful LCS programs implemented a toll free number for coordinators to address patient inquiries (49). Besides the logistical advantages of advanced nurse practitioners, there may be an economic benefit as well. Gilbert and colleagues examined the economic impact of a nurse practitioner directed LCS program, discovering increased revenue for their Thoracic Surgery and Interventional Pulmonary divisions primarily generated from newly identified diseases and the subsequent evaluations, procedures, and surgeries (52).

A strong multidisciplinary presence within an LCS program's leadership is imperative and emphasized by several of the implemented programs $(32,47,53,54)$. Leadership responsibility includes the development of a self-sustaining infrastructure with protocols in place to limit inconsistences in patient care. Within a VA health system, a review of several LCS participating sites revealed 


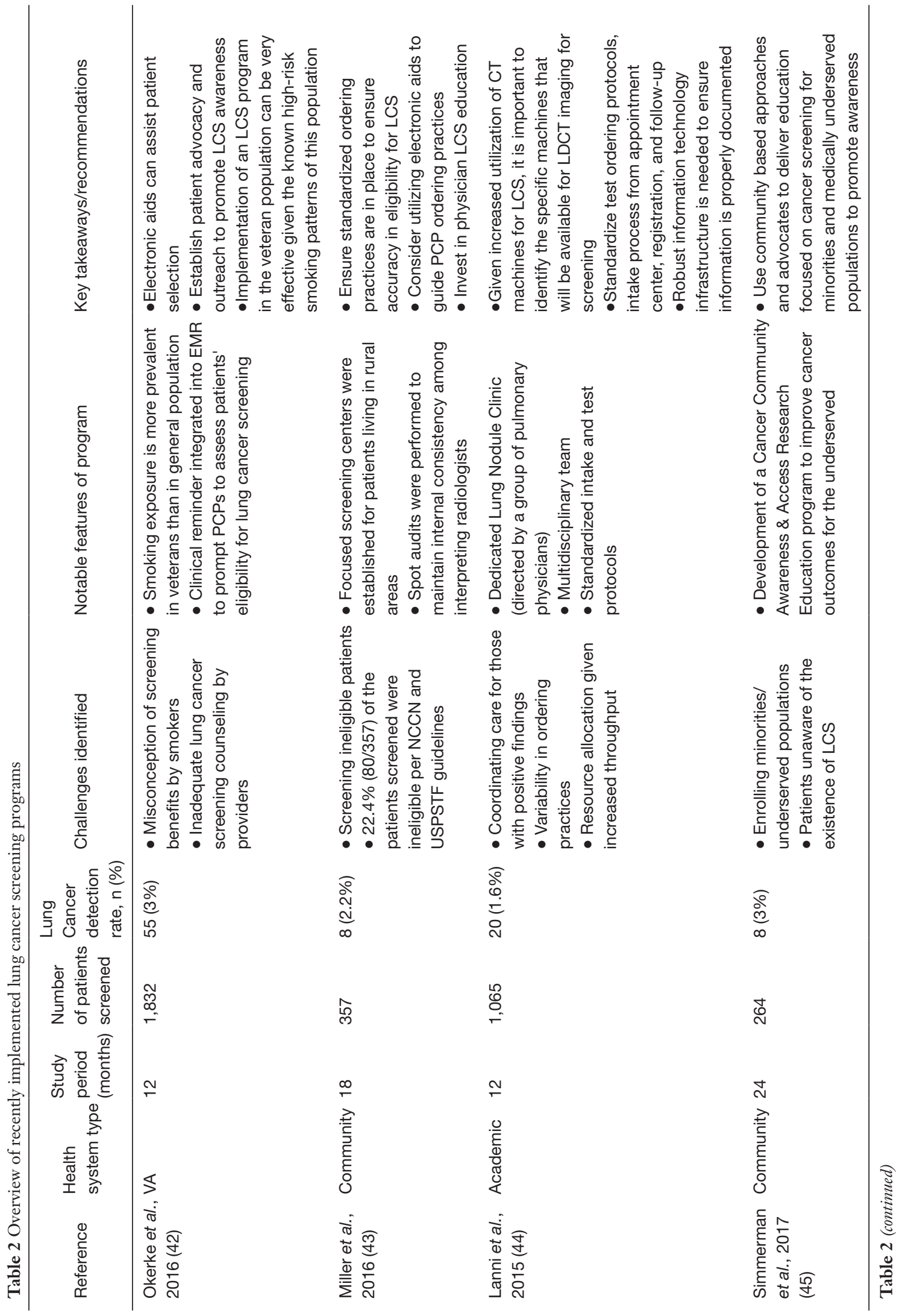




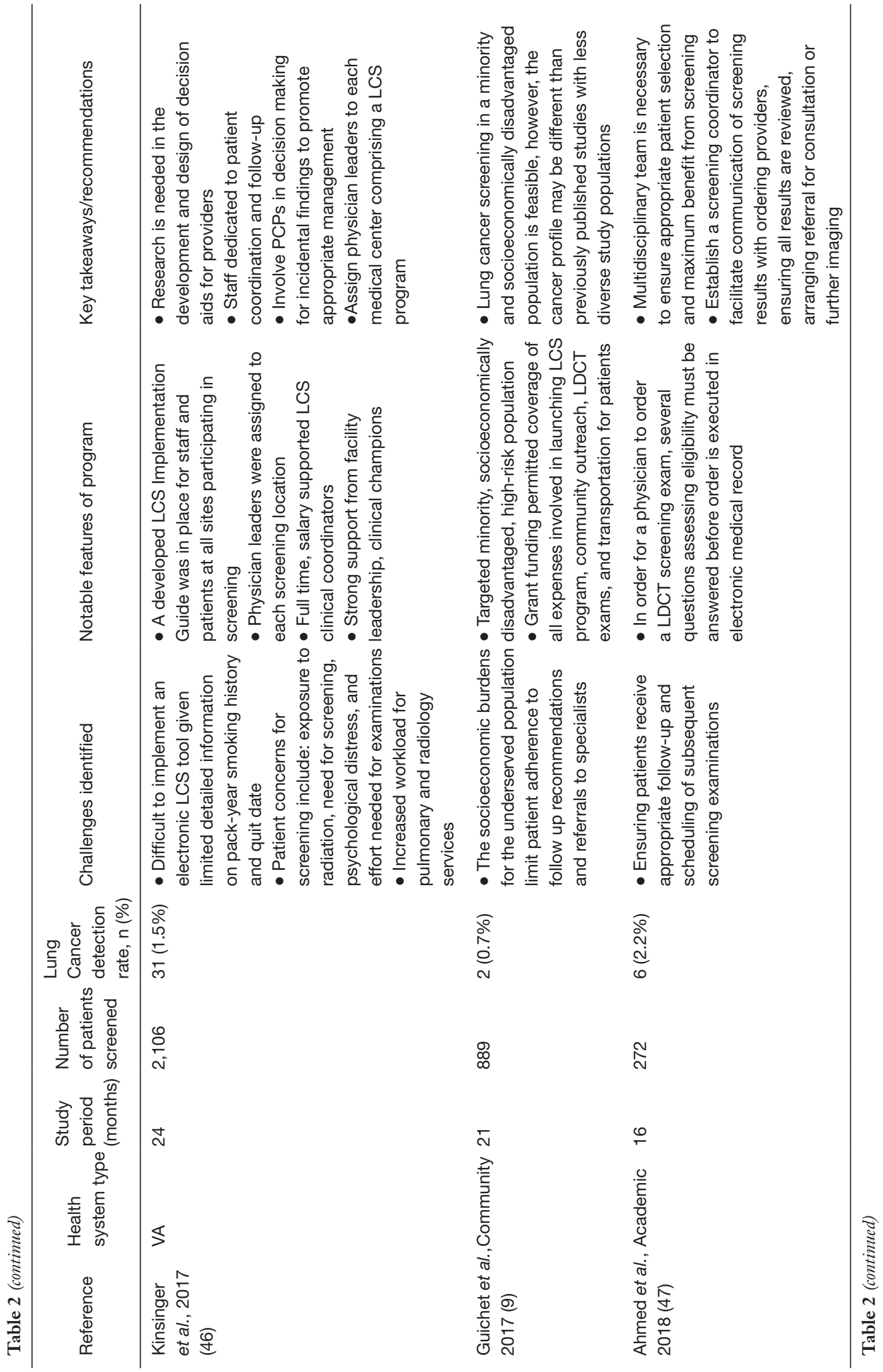



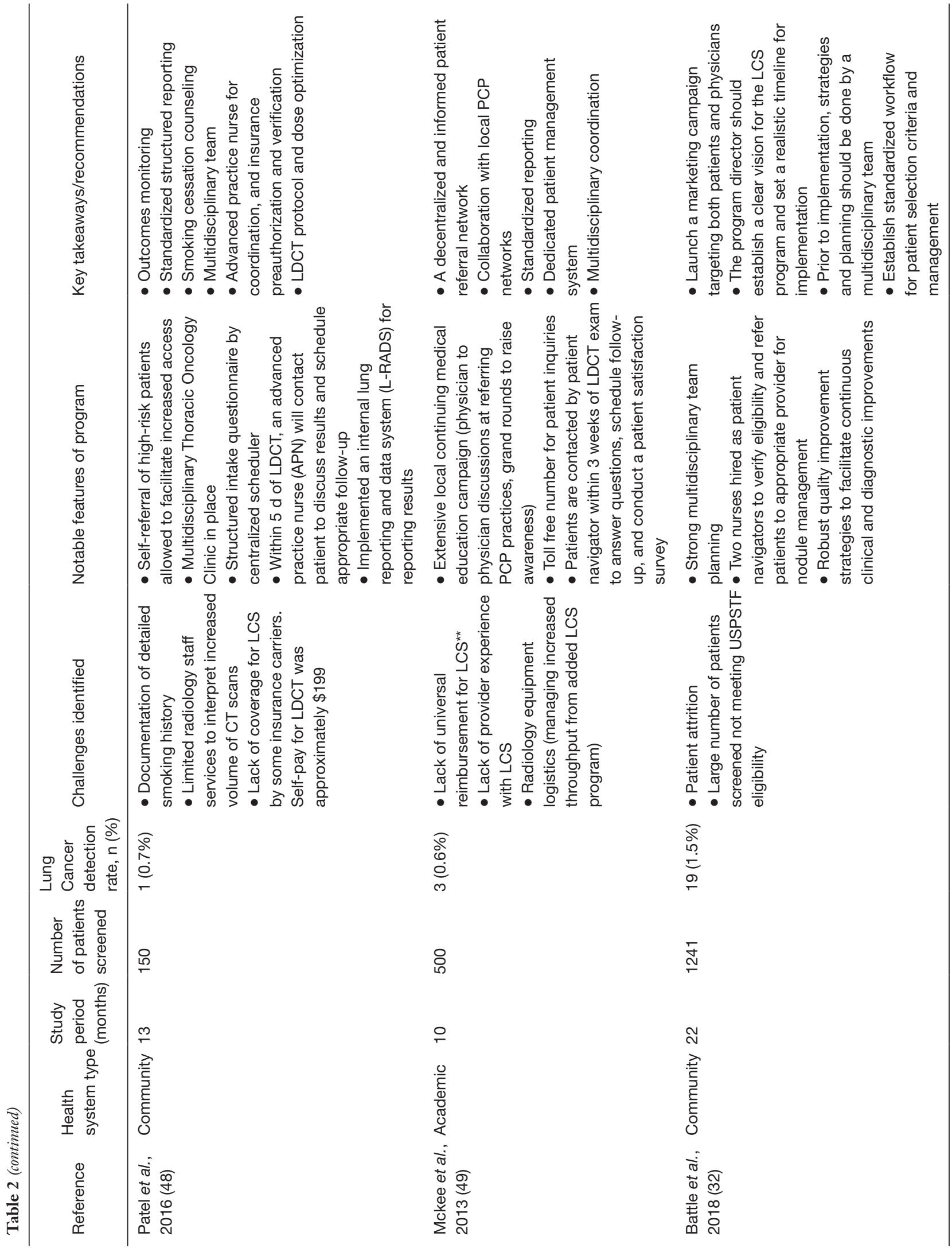

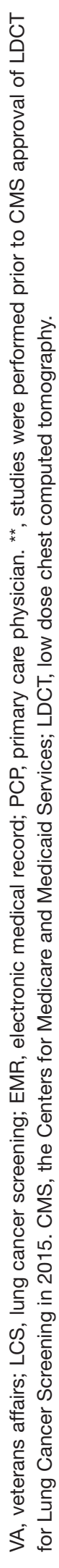
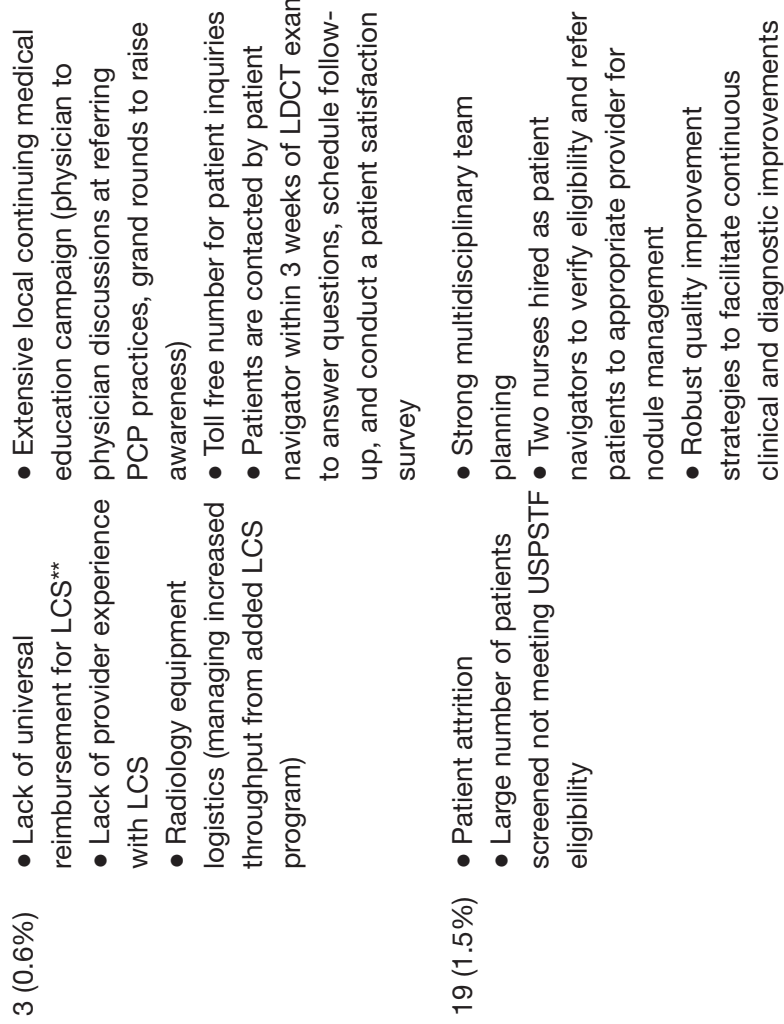

$\widehat{0}$
$\stackrel{0}{\circ}$
움
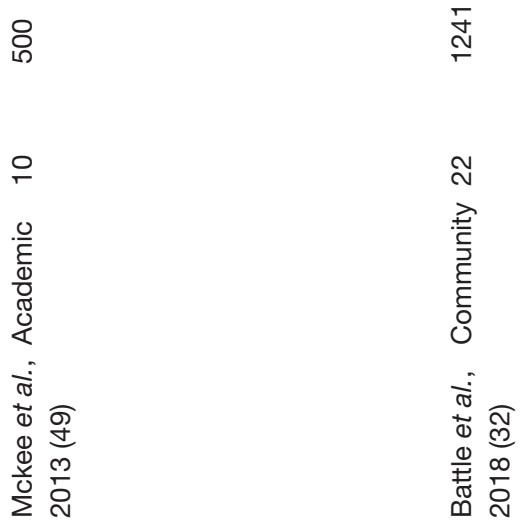
inconsistencies in patient selection and the utilization of quality audits (55). The complexity of implementing an LCS program within an institution comprised of multiple medical centers is largely attributable to inherent variations in medical practice. In this context, it is vital for program leadership to assign physician leaders at each participating site within a program to distribute and enforce polices regarding patient selection, physician referral, imaging protocols, shared decision making, smoking cessation services, and management of positive findings on LDCT (46). Additionally, an increase in LCS uptake will naturally lead to increased workload on staff and resources $(46,48)$. As the throughput for LCS increases for any given program, it is essential for the leadership team to manage resource allocation and make additions if needed.

The prevalence of smoking is known to be higher amongst minorities and those that are socioeconomically disadvantaged (56). A responsible and effective LCS program will allocate resources to assist this vulnerable population. Guichet et al. reported their experience in targeting underserved populations, revealing socioeconomic burdens as a barrier to patient adherence to recommendations and referrals to specialists (9). LCS programs should focus on community outreach and social services for these individuals to promote LCS awareness and to clarify the commonly misconceived notion that screening will be an expensive burden $(21,45)$.

\section{The future of LCS}

With the ubiquitous nature of technology in patient care, a natural progression is the implementation of electronic aids to assist physician decision making (43). Ahmed and colleagues described the utilization of an electronic questionnaire that must be completed by a provider wishing to order a LDCT as an attempt to enforce appropriate screening (47). Others have incorporated computerized clinical reminders for physicians regarding patient current or recent smoking (57). However, there remain challenges in capturing detailed smoking history (pack-years and years since quitting) within the electronic medical record for these aids to be beneficial for LCS (46). Electronic aids are undoubtedly innovative and promising, however, little is known regarding their feasibility, scalability, and efficacy.

Another opportunity to improve LCS is broadening the points of referral. Currently, identifying eligible high-risk individuals for LCS is dependent on PCPs. An interesting concept may be expanding the responsibility of LCS enrollment to specialties beyond primary care. Emergency Departments (ED) have emerged as an important community resource for implementing preventative healthcare services (58). Further, ED patients smoke at rates far in excess of the national average, as high as 48\% (59). Accordingly, the ED would appear to be an ideal platform to capture many high-risk smokers that would benefit from LDCT LCS. Furthermore, an important aspect of utilizing the ED as a resource for enrollment is the large volume of socioeconomically disadvantaged, racial and ethnic minorities who seek care in the ED (60). Often the ED is the only point of interaction with the healthcare system for these individuals. In this context, the ED has long been identified as an important public health platform for assessing patients' smoking status, offering brief advice to quit, and referring patients to smoking cessation programs $(58,59)$. However, there is limited information regarding the ED's ability to identify and refer eligible patients for LCS (61).

\section{Conclusions}

Regardless of the convincing evidence supporting LDCT screening for high-risk patients, there continues to be a discrepancy in enrollment not seen in other cancer screening programs. Undoubtedly, there are a variety of challenges for patients, providers, and medical systems. However, many of these challenges can be overcome through a concerted effort from providers and healthcare leadership. Depending on the healthcare system and resources available, there are certainly unique considerations that must be made when implementing an LCS program. However, the general core principles have been outlined in this review.

\section{Acknowledgments}

Funding: None.

\section{Footnote}

Conflicts of Interest: All authors have completed the ICMJE uniform disclosure form (available at https://ccts. amegroups.com/article/view/10.21037/ccts-20-47/coif). MR reports personal fees from Intuitive Surgical outside the submitted work. The other authors have no conflicts of interest to declare.

Ethical Statement: The authors are accountable for all 
aspects of the work in ensuring that questions related to the accuracy or integrity of any part of the work are appropriately investigated and resolved.

Open Access Statement: This is an Open Access article distributed in accordance with the Creative Commons Attribution-NonCommercial-NoDerivs 4.0 International License (CC BY-NC-ND 4.0), which permits the noncommercial replication and distribution of the article with the strict proviso that no changes or edits are made and the original work is properly cited (including links to both the formal publication through the relevant DOI and the license). See: https://creativecommons.org/licenses/by-nc-nd/4.0/.

\section{References}

1. Siegel RL, Miller KD, Jemal A. Cancer statistics, 2016. CA Cancer J Clin 2016;66:7-30.

2. Humphrey LL, Deffebach M, Pappas M, et al. Screening for lung cancer with low-dose computed tomography: a systematic review to update the US Preventive services task force recommendation. Ann Intern Med 2013;159:411-20.

3. Lin JJ, Cardarella S, Lydon CA, et al. Five-year survival in EGFR-mutant metastatic lung adenocarcinoma treated with EGFR-TKIs. J Thorac Oncol 2016;11:556-65.

4. Janssen-Heijnen ML, Coebergh JWW. Trends in incidence and prognosis of the histological subtypes of lung cancer in North America, Australia, New Zealand and Europe. Lung Cancer 2001;31:123-37.

5. Grondin SC, Edwards JP, Rocco G. Surgeons and lung cancer screening: rules of engagement. Thorac Surg Clin 2015;25:175-84.

6. Fontana RS, Sanderson DR, Woolner LB, et al. Lung cancer screening: the Mayo program. J Occup Med 1986;28:746-50.

7. Tockman MS. Survival and mortality from lung cancer in a screened population: the Johns Hopkins study. Chest 1986;89:324S-5S.

8. Team NLSTR. Reduced lung-cancer mortality with lowdose computed tomographic screening. $\mathrm{N}$ Engl J Med 2011;365:395-409.

9. Guichet PL, Liu BY, Desai B, et al. Preliminary results of lung cancer screening in a socioeconomically disadvantaged population. AJR Am J Roentgenol 2018;210:489-96.

10. Goulart BH, Bensink ME, Mummy DG, et al. Lung cancer screening with low-dose computed tomography: costs, national expenditures, and cost-effectiveness. J Natl
Compr Canc Netw 2012;10:267-75.

11. Warner E. Breast-cancer screening. N Engl J Med 2011;365:1025-32.

12. Richardson A. Screening and the number needed to treat. J Med Screen 2001;8:125-7.

13. Moyer VA. Screening for lung cancer: US Preventive Services Task Force recommendation statement. Ann Intern Med 2014;160:330-8.

14. Wood DE. National Comprehensive Cancer Network (NCCN) clinical practice guidelines for lung cancer screening. Thorac Surg Clin 2015;25:185-97.

15. Berg AO, Allan JD, Frame P, et al. Lung cancer screening: recommendation statement. Ann Intern Med 2004;140:738.

16. de Koning HJ, van der Aalst CM, de Jong PA, et al. Reduced lung-cancer mortality with volume CT screening in a randomized trial. N Engl J Med 2020;382:503-13.

17. Jemal A, Fedewa SA. Lung cancer screening with lowdose computed tomography in the United States-2010 to 2015. JAMA Oncol 2017;3:1278-81.

18. Ali N, Lifford KJ, Carter B, et al. Barriers to uptake among high-risk individuals declining participation in lung cancer screening: a mixed methods analysis of the UK Lung Cancer Screening (UKLS) trial. BMJ open 2015;5:e008254.

19. Mandal R, Basu P. Cancer screening and early diagnosis in low and middle income countries : Current situation and future perspectives. Krebsvorsorge und Früherkennung in Ländern mit niedrigem und mittlerem Einkommen : Aktuelles Szenario und Zukunftsperspektiven. Bundesgesundheitsblatt Gesundheitsforschung Gesundheitsschutz 2018;61:1505-12.

20. Carter-Harris L, Gould MK. Multilevel barriers to the successful implementation of lung cancer screening: why does it have to be so hard? Ann Am Thorac Soc 2017;14:1261-5.

21. Simmons VN, Gray JE, Schabath MB, et al. High-risk community and primary care providers knowledge about and barriers to low-dose computed topography lung cancer screening. Lung Cancer 2017;106:42-9.

22. Crothers K, Kross EK, Reisch LM, et al. Patients' attitudes regarding lung cancer screening and decision aids. A survey and focus group study. Ann Am Thorac Soc 2016;13:1992-2001.

23. Carter $\square$ Harris L. Lung cancer stigma as a barrier to medical help $\square$ seeking behavior: Practice implications. J Am Assoc Nurse Pract 2015;27:240-5.

24. Carter $\square$ Harris L, Ceppa DP, Hanna N, et al. Lung cancer 
screening: what do long $\square$ term smokers know and believe? Health Expect 2017;20:59-68.

25. Harwood GA, Salsberry P, Ferketich AK, et al. Cigarette smoking, socioeconomic status, and psychosocial factors: examining a conceptual framework. Public Health Nurs 2007;24:361-71.

26. Katz SJ, Hofer TP. Socioeconomic disparities in preventive care persist despite universal coverage: breast and cervical cancer screening in Ontario and the United States. JAMA 1994;272:530-4.

27. Hoffman RM, Sussman AL, Getrich CM, et al. Attitudes and Beliefs of Primary Care Providers in New Mexico About Lung Cancer Screening Using Low-Dose Computed Tomography [published correction appears in Prev Chronic Dis. 2019 Nov 07;16:E149]. Prev Chronic Dis 2015;12:E108.

28. Tong BC. Lung cancer screening: No more excuses. J Thorac Cardiovasc Surg 2018;155:369ロ70.

29. Physicians AAoF. Clinical preventative service recommendation: Lung Cancer. Available online: https:// www.aafp.org/patient-care/clinical-recommendations/all/ lung-cancer.html. Accessed December 23, 2019.

30. Jokerst C, Oliva I, Mohammed TL. Clearing the air: steps for lung cancer screening success. Curr Probl Diagn Radiol 2015;44:113-7.

31. Fintelmann FJ, Bernheim A, Digumarthy SR, et al. The 10 pillars of lung cancer screening: rationale and logistics of a lung cancer screening program. Radiographics 2015;35:1893-908.

32. Batlle JC, Maroules CD, Latif MA, et al. A five-step strategy for building an LDCT lung cancer screening program. Appl Radiol 2018;47:12-8.

33. Kazerooni EA, Armstrong MR, Amorosa JK, et al. ACR $\mathrm{CT}$ accreditation program and the lung cancer screening program designation. J Am Coll Radiol 2015;12:38-42.

34. Services DoHH. Quality Payment Program. Available online: https://qpp.cms.gov/mips/overview. Accessed February 24, 2020.

35. Mazzone P, Powell CA, Arenberg D, et al. Components necessary for high-quality lung cancer screening: American College of Chest Physicians and American Thoracic Society policy statement. Chest 2015;147:295-303.

36. Tanoue LT, Tanner NT, Gould MK, et al. Lung cancer screening. Am J Respir Crit Care Med 2015;191:19-33.

37. Pedersen JH, Ashraf H. Implementation and organization of lung cancer screening. Ann Transl Med 2016;4:152.

38. Ramsey SD, Malin JL, Goulart B, et al. Implementing lung cancer screening using low-dose computed tomography: recommendations from an expert panel. J Oncol Pract 2015;11:e44-9.

39. Goulart BH. The value of lung cancer CT screening: it is all about implementation. Am Soc Clin Oncol Educ Book 2015;35:e426-33.

40. McKee BJ, McKee AB, Kitts AB, et al. Low-dose computed tomography screening for lung cancer in a clinical setting: essential elements of a screening program. J Thorac Imaging 2015;30:115-29.

41. Martin MD, Kanne JP, Broderick LS, et al. Lung-RADS: pushing the limits. Radiographics 2017;37:1975-93.

42. Okereke IC, Bates MF, Jankowich MD, et al. Effects of implementation of lung cancer screening at one veterans affairs medical center. Chest 2016;150:1023-9.

43. Miller AT, Kruger P, Conner K, et al. Initial outcomes of a lung cancer screening program in an integrated community health system. J Am Coll Radiol 2016;13:733-7.

44. Lanni TB, Stevens C, Farah M, et al. Early Results From the Implementation of a Lung Cancer Screening Program. Am J Clin Oncol 2018;41:218-22.

45. Simmerman E, Thomson N, Dillard T, et al. Free Lung Cancer Screening Trends Toward a Twofold Increase in Lung Cancer Prevalence in the Underserved Southeastern United States. South Med J 2017;110:188-94.

46. Kinsinger LS, Anderson C, Kim J, et al. Implementation of lung cancer screening in the Veterans Health Administration. JAMA Intern Med 2017;177:399-406.

47. Ahmed A, Verma N, Barreto I, et al. Low-dose Lung Cancer Screening at an Academic Medical Center: Initial Experience and Dose Reduction Strategies. Aca-demic Radiology 2018;25:1025-30.

48. Patel S, Cho A, Lamont A, et al. Implementing a community hospital lung cancer screening program: a multidisciplinary program and a standardized reporting system. J Am Coll Radiol 2016;13:R14-7.

49. McKee BJ, McKee AB, Flacke S, et al. Initial experience with a free, high-volume, low-dose CT lung cancer screening program. J Am Coll Radiol 2013;10:586-92.

50. Ersek JL, Eberth JM, McDonnell KK, et al. Knowledge of, attitudes toward, and use of low-dose computed tomography for lung cancer screening among family phy-sicians. Cancer 2016;122:2324-31.

51. Korst RJ. Systematic approach to the management of the newly found nodule on screening computed tomography: role of dedicated pulmonary nodule clinics. Thorac Surg Clin 2013;23:141-52.

52. Gilbert CR, Ely R, Fathi JT, et al. The economic impact of a nurse practitioner-directed lung cancer screening, 
incidental pulmonary nodule, and tobacco-cessation clinic. J Thorac Cardiovasc Surg 2018;155:416-24.

53. Gillaspie EA, Allen MS. Computed tomographic screening for lung cancer: the Mayo Clinic experience. Thorac Surg Clin 2015;25:121-7.

54. Milch H, Kaminetzky M, Pak P, et al. Computed tomography screening for lung cancer: preliminary results in a diverse urban population. J Thorac Imaging 2015;30:157-63.

55. Gesthalter YB, Koppelman E, Bolton R, et al. Evaluations of Implementation at Early-Adopting Lung Cancer Screening Programs: Lessons Learned. Chest 2017;152:70-80.

56. Hiscock R, Bauld L, Amos A, et al. Socioeconomic status and smoking: a review. Ann N Y Acad Sci 2012;1248:107-23.

57. Fung CH, Woods JN, Asch SM, et al. Variation in implementation and use of computerized clinical reminders in an integrated healthcare system. Am J Manag

doi: $10.21037 /$ ccts-20-47

Cite this article as: Patel DC, Ramsey M, Phadke A, Lui NS. Challenges in lung cancer screening: a review of implemented programs. Curr Chall Thorac Surg 2021;3:6.
Care 2004;10:878-85.

58. Bernstein SL, Becker BM. Preventive care in the emergency department: diagnosis and management of smoking and smoking $\square$ related illness in the emergency department: a systematic review. Acad Emerg Med 2002;9:720-9.

59. Bernstein SL, Boudreaux ED, Cydulka RK, et al. Tobacco control interventions in the emergency department: a joint statement of emergency medicine organizations. Ann Emerg Med 2006;48:e417-26.

60. Kocher KE, Nallamothu BK, Birkmeyer JD, et al. Emergency department visits after surgery are common for Medicare patients, suggesting opportunities to improve care. Health Aff (Millwood) 2013;32:1600-7.

61. Cunningham RM, Bernstein SL, Walton M, et al. Alcohol, tobacco, and other drugs: future directions for screening and intervention in the emergency department. Acad Emerg Med 2009;16:1078-88. 